Biol Neonat 1990;58(suppl 1):I-III

\title{
Contents, Vol. 58, Supplement 1, 1990
}

\section{Introduction}

Rubaltelli, F.F 1

Metabolic Adaptations to Change of Nutrition at Birth

Girard,J 3

Neonatal Hypoglycemia

Sann, L $\quad 16$

Human Neonatal Hypocalcemia

Salle, B.L.; Delvin E.; Glorieux, F.; David, L

Management of Neonatal Hyperbilirubinemia: Rational Use of Phototherapy

Polin, R.A 32

Clinical Approach to Inherited Metabolic Disorders in Neonates

Saudubray, J.M.; Narcy, C; Lyonnet, L.; Bonnefont, J.P.; Poll The, B.T.; Munnich, A

Mitochondrial Defects of Brain and Muscle

De Vivo. D.C.; DiMauro, S 54

Sudden Infant Death Syndrome and Inherited Disorders of Fatty Acid ß-Oxidation

Harpey, J.-P.; Charpentier, C; Paturneau-Jouas, M 70

Carnitine and Total Parenteral Nutrition of the Neonate

Schmidt-Sommerfeld, E.; Penn, D 81

Carnitine Supplementation in Soy-Based Formula-Fed Infants

Novak, M

89

Carnitine Supplementation in the Premature

Melegh, B 93

Author Index 107

Subject Index 108 